\title{
Acercamientos a la representación de la infancia y la homosexualidad en Los mástiles de Jorge López Páez
}

\author{
Jorge Muñoz Figueroa \\ CEPE/FFYL, UNAM
}

Resumen: Este artículo analiza dos aspectos específicos -infancia y homosexualidad-en el libro Los mástiles (1955), la primera colección de cuentos escritos por Jorge López Páez (Veracruz, 1922). Eventualmente, ambos temas se hicieron recurrentes en su obra y han adquirido especial atención en la literatura mexicana a partir de la segunda mitad del siglo XX. Varios críticos literarios han delineado el corpus de obras que presentan estos dos temas, ya que ambos incrementaron su importancia y presencia en la literatura de manera paulatina.

Sin embargo, aquellos que se han dedicado al estudio de estos temas han señalado reiteradamente que es necesario lograr una mejor y más amplia investigación con el objetivo de incluir obras literarias y autores que han sido escasamente considerados, que es precisamente el caso de Jorge López Páez. En este artículo se destacan los recursos literarios que fueron empleados en esta colección de cuentos, y pretende mostrar a este autor veracruzano como un referente obligado en lo que respecta a estos dos temas en la literatura mexicana contemporánea.

Palabras clave: literatura mexicana, cuento, infancia, homosexualidad.

\begin{abstract}
This paper analyzes two specific aspects -childhood and homosexuality- in Los mástiles (1955), Jorge López Páez's first collection of short stories. Both motifs eventually became recurrent in his writing, and have gained special attention in Mexican literature during the second half of the Twentieth Century. Several literary critics have traced the corpus of works that presents either one of these two topics as a theme, since both have gradually increased their importance and presence in the literature corpus.
\end{abstract}

1 El presente trabajo pertenece a una investigación más amplia sobre la representación de la infancia en la literatura mexicana del siglo XX. 
However, those who have studied these aspects have repeatedly pointed out that it is necessary to have a wider and better research in order to include literary works and authors that have scarcely been studied, which is Jorge López Páez's (Veracruz, 1922) case. The following analysis highlights the literary aspects applied to this collection of short stories, and pretends to pintpoint this author as one essential reference concerning these two subjects within the contemporary Mexican Literature.

Key words: Mexican literature, short story, childhood, homosexuality.

Jorge López Páez ha consolidado la representación de la infancia en su extensa obra, aspecto que considero una de sus vertientes predilectas u obsesiones narrativas, según se vea. La importancia de los personajes infantiles (e incluso adolescentes) y la vasta reformulación que realiza del tema expone los aspectos significativos que ocupan a los actores principales: los miedos y la soledad que padecen, los juegos y las relaciones de poder que experimentan y ensayan (observadas y heredadas de los adultos), los diálogos (o silencios) empleados para comunicarse, etcétera.

Esta recurrencia es notable si tomamos en cuenta que la obra del veracruzano la conforman veinte libros, de los cuales en seis novelas y en casi dos docenas de cuentos los infantes y algunos adolescentes son los protagonistas. En casi la mitad de toda su obra, el autor detalla los recursos empleados por los adultos para relegar a los menores en las soledades y temores que serán recuperados años después en las evocaciones realizadas por los narradores; éstos buscan restituir las limitaciones infantiles de aquellos años para entender las situaciones que los han marcado y que constituyen el resorte para embarcarse en los vericuetos de la memoria. Estas limitaciones, puntualizo, implican ciertas técnicas narrativas que López Páez emplea y domina, según veremos en las próximas páginas.

EN EL PRINCIPIO FUERON LOS MÁSTILES (1955)

El inicio de la trayectoria de Jorge López Páez se reconoce, sin embargo, con la aparición de una obra de teatro llamada "La última visita", esto en 1951; previo a esta fecha, el propio autor menciona:"había yo publicado primero un cuentecito, que no está recogido en ningún lado, que se llama 'El que espera'; era una hojita que pasábamos ahí con unos amigos, que hacíamos una edición que se llamaba 
'Los Presentes.'"2 Posteriormente, continúa explicando López Páez, "me invitó Arreola y publiqué un librito de cuentos que se llama Los mástiles", en 1955.

Este "librito" de 75 páginas de caja chica y letra grande consta de tres relatos: "Frescas y dulces aguas", "Hormigas" y "El chupamirto"; 4 en ellos asoma ya el estilo que distinguirá al joven escritor: la infancia y las sensaciones de esos recuerdos como los conductores de la narración, así como el uso de personajes infantiles en sus historias, donde tienen un papel central. Asimismo, en Los mástiles se muestra la vida en tierras tropicales, con costumbres rígidas y con las diferencias sociales muy marcadas. Los protagonistas se enfrentan al mundo adulto y a las incomprensibles actitudes de los mayores; viven (y padecen) su mundo cotidiano y los retos inmediatos.

Sobre este libro, que inaugura una destacada trayectoria en la literatura mexicana de la segunda mitad del siglo XX, existen muy pocas menciones y aún menos estudiosos que lo hayan trabajado, de ahí que sean valiosas las palabras que le dedica la investigadora Edith Negrín, quien ha expresado que

Los cuentos [...] permiten atisbar el universo de un chico provinciano, en la edad de la pubertad. La naturaleza tropical —el río, las flores, los animalesenmarca tres episodios, en los cuales sendos protagonistas, con distintos nombres, pero con idéntica sensibilidad, viven las emociones que acompañan la entrada a la adolescencia: la vergüenza, el miedo, la frustración y el deseo reprimido. Los tres relatos son muy buenos [...] La obra de López Páez merece ser más estudiada. ${ }^{5}$

En una revisión que Negrín hace del cuento mexicano de 1954 a 1957, destaca la calidad de los relatos y se une a las contadas voces que solicitan mayor atención a la prosa del veracruzano; dado que su comentario hace señalamientos del primer texto, retomaré su opinión más adelante.

Considero que los cuentos de Los mástiles resultan un "muestrario" de voces narrativas: las acciones de "Frescas y dulces aguas" son relatadas retrospectivamente por un narrador externo y ajeno a la acción de los personajes, lo cual le permite realizar observaciones que no podrían ni enunciar

2 Jorge López Páez, Entrevista personal. Sobre El solitario Atlántico y Mi hermano Carlos. 6 de noviembre del 2000.

3 Loc. cit.

4 "El chupamirto" aparecerá de nuevo en dos libros, tanto en una Antología (2002) publicada por la UNAM, como en el libro El chupamirto y otros cuentos (2010) dentro de la Colección Centzontle del FCE. Este último volumen fue un intento de reimpresión de Los mástiles, tal como me lo comentó el maestro López Páez en 2008; sin embargo, la publicación se demoró y sufrió cambios sustanciales, pues sólo se conservó el cuento que da título al libro.

5 Edith Negrín, “Cuentos para vencer a la muerte”, p. 67. 
ni considerar los involucrados; en el caso de "Hormigas", quien nos entera de las acciones es el protagonista mediante una narración intercalada, es decir que relata lo que le ocurre y/o piensa al momento (narración simultánea) y en ocasiones se desliza hacia la narración retrospectiva, aunque el pasado sea muy cercano; por último, en "El chupamirto" el autor veracruzano nos entrega al que será el tipo de enunciador emblemático en la primera etapa de su trayectoria: el "yo adulto" que recrea las limitaciones del "yo niño". Este tipo de narrador (con frecuencia confundido con el personaje) ofrece una "engañosa" narración consonante, pues basta con unas cuantas palabras, con alguna declaración para que claramente se manifieste como un sujeto que ya no es un infante, pero que recupera en buena medida las sensaciones y restricciones de su "yo narrado" desde su presente de enunciación, como lo veremos más adelante en muchos relatos y novelas como El solitario Atlántico (1958), Mi hermano Carlos (1965) y La costa (1980).

A la par de mostrar distintas voces narrativas, Los mástiles ofrece varios asuntos a considerar para este texto: ciertos guiños homosexuales, ${ }^{6}$ los miedos de los infantes, los juegos como relaciones de poder que imitan las dinámicas establecidas y aceptadas por los adultos, así como la soledad y la marginación que padecen los protagonistas de los relatos.

Aunado a lo anterior, es de capital importancia reparar en otro aspecto que comparten los tres cuentos: los animales. Si bien el primer título habla de las aguas, el motor de la anécdota es conseguir peces, y al reparar en los insectos y en un pequeño pájaro que dan nombres a los relatos restantes, es innegable el peso de estos seres en las metáforas, no sólo a nivel de frase, que emplea López Páez en su primera colección de narraciones. Una vez señaladas las posibilidades que los tres casos presentan, procedo a revisar los dos primeros para enfocarme

6 Críticos como Mario Muñoz, Vicente Francisco Torres e Ignacio Trejo Fuentes han revisado y registrado el auge de la narrativa (novelas y cuentos) con personajes y temas que dan vida a un mundo que ya se venía configurando lentamente y que deja de ser marginal. Me parece oportuno referir a Mario Muñoz sobre este punto para, brevemente, dar noticias sobre este corpus inicial: "La paulatina liberación de la moral mercenaria, permitió que fueran publicándose por esos años las primeras novelas gays escritas en México como El Diario de José Toledo, de Miguel Barbachano Ponce, en 1964, y Después de todo, de José Ceballos Maldonado, en 1969. De modo tangencial otros novelistas habían tocado el tema, pero sin la hondura de los dos mencionados modelos narrativos, precursores indiscutibles de Luis Zapata. Pienso, por ejemplo, en El norte (1956) de Emilio Carballido, en La comparsa, de Sergio Galindo, y en el relato "A la víbora de la mar", contenido en Cantar de ciegos, de Carlos Fuentes, ambos libros de 1964. Esta coincidencia de circunstancias sociales, culturales y literarias, explica la curva ascendente del discurso que alude a la homosexualidad y la creciente formación de un imaginario que va integrándose con los aportes de novelas y cuentos de variado alcance estético." Mario Muñoz, "El cuento mexicano de tema homosexual", p.122. 
en aspectos concretos de representación de la infancia y la homosexualidad en el primer libro de Jorge López Páez.

\section{"FresCAS Y DULCES AGUAS": ENTRE RITOS Y DESEO}

En el primer relato encontramos una sutil referencia a un deseo homoerótico por parte de uno de los protagonistas: Joaquín. La anécdota del relato involucra a tres amigos, infantes de no más de 10 u 11 años, quienes deciden ir a "pescar", aunque lo que pretenden es regresar con los peces vivos; luego de emprender el camino al río con ciertas dudas y algunos contratiempos (sobre todo porque van sin permiso de los adultos), un conocido (el curtidor del pueblo) los anima a seguir una vereda para encontrar a su hijo Félix, quien los guiará en la búsqueda de un lugar idóneo para pescar. En efecto, lo encuentran y éste los lleva a un espacio apartado, hermoso e incluso iniciático; luego de experimentar una gran fascinación por el lugar, consiguen atrapar unos cuantos peces para luego regresar y despedirse de su guía. Tal ha sido la impresión que ha guardado Joaquín, que sueña con una imagen muy peculiar de Félix, lo cual, lejos de ser un final, parece un comienzo.

Lo que se antoja como una mera expedición donde los juegos y la diversión ocuparán el tiempo de los personajes (pues al tratarse de niños sería muy evidente y dentro de las expectativas del lector), resulta una jornada de pesca constantemente invadida por el temor que ataca a los participantes; a cada nuevo giro que deben enfrentarse, lo hacen invadidos por el miedo ya sea a los obstáculos, al juicio adulto o a las funestas consecuencias que los inmovilizan para seguir con el viaje a pescar. Aquí la primera cita del cuento, casi al inicio:

- ¿Dónde conseguiremos en qué traerlos? - preguntó Enrique. Se imaginó, de repente, obligado a ofrecer una jarra. En su imaginación solo vió la jarra de porcelana, y los riesgos que traería: burlar a su madre, a sus hermanos, a la criada (¿y si se rompe?). ${ }^{7}$

La expedición parece marcada por señales funestas, tal como ocurre al romper una maceta de la abuela de uno de ellos, lo cual puede traer el castigo de las figuras de autoridad; nótese, además, el tono enigmático en las primeras líneas:

7 Jorge López Páez, “Frescas y dulces aguas”, p. 9. En lo sucesivo, sólo se anotará la página entre paréntesis al final de la cita; además, se respeta la acentuación original de algunos monosílabos. 
Se vieron unos a otros, la sensación de admonición, de augurio, les provocó un estremecimiento, como si algo, entre los arbustos del jardín, algo oculto y misterioso, impidiera su viaje.

-Ya no... No terminó la frase Enrique.

— ¡Sí, sí vas, marica! —le espetó Joaquín—, nadie se raja, el que se raje: que le caiga...

Ante un mal futuro, misterioso e impredecible, aunando sus esfuerzos, ocultaron los restos de la maceta, y enterraron la planta, como si la fuentecita del jardín, la mosqueta, las bugambilias, las violetas, los naranjos, todo, les acechara, como si fueran los cómplices determinados a traicionarlos. (p. 11)

En esta escapada, los adultos aparecen como obstáculos que hay que librar, de ahí que la aparición de don Julián, el curtidor, parece uno más: "Enrique no supo qué contestar. Si respondía, en cualquier forma, negativa o positivamente, corría el peligro de ser denunciado, pues si don Julián llegaba a su casa preguntando por su padre, le diría a éste que su hijo..." (p. 13). Sin embargo, resulta un facilitador, un aliado oportuno para los fines de los protagonistas, sobre todo porque les indica el sitio donde encontrarán a quien los conducirá a un sitio seguro:

Estos reanudaron su carrera, uno tras otro por la sombría vereda, a través de la finca de café. Estaban a unos cuando metros del río, el correr del agua se oía claramente. De repente el cafetal se interrumpió y en una parte descubierta, secándose al sol, estaba desnudo Félix, el hijo de don Julián. (p. 14)

Los niños y Félix se conocían de vista, lo cual impide un extrañamiento total en el encuentro, aunque no dejamos de reparar en que los niños del pueblo (vestidos) tienen ante sí a un chico (desnudo) que es más cercano a la naturaleza que ellos; entablar comunicación implica pasar por alto que su potencial guía esté sin ropa, un primer obstáculo que vencen apenas con unas palabras, mismas que constituyen un primer pacto en esta naciente relación:

— ¿Qué tal está el agua?- preguntó Juan.

-Tibia — respondió Félix-. ¿Por qué no se bañan?

La amistad se había concertado. En el pasto verde, en cuatro montoncitos quedaron sus ropas. La brisa del río acarició sus cuerpos. Félix, tiritando, con sus brazos apretados al cuerpo, veía a los niños del pueblo.

Juan, seguido de Enrique y de Joaquín, se acercó al borde de la pocita. Salvo por la sombra de un álamo que dibujaba sus ramas oscuras en ella, todo era reflejos y luz. (pp. 14-15)

Este encuentro muestra la dicotomía luz/oscuridad en esta expedición, misma que observamos desde la cita anterior, donde los niños parten de lo conocido 
para adentrarse paulatinamente en lo inesperado y ajeno; a pesar de que transiten por lugares oscuros ("por la sombría vereda") o estén a unos metros de ellos ("la sombra de un álamo que dibujaba sus ramas oscuras en ella [la pocita]"), la claridad no desaparece y de alguna forma los ampara ("el cafetal se interrumpió" y dejaron atrás la sombra o mientras se bañaban "todo era reflejos y luz").

Más significativa aún es la entrada al agua: participan de una purificación previa al cruzamiento del umbral que Félix les mostrará más adelante. ${ }^{8}$ No sólo se realiza un juego que facilita la interacción entre los chicos, sino que se muestra cómo han aceptado al hijo del curtidor como alguien que puede verlos desnudos e iniciarlos en este viaje. Desde este punto es obligado percatarnos de la relevancia del ruido que viene desde el mundo y actores conocidos (la actividad de las lavanderas a cierta distancia), mismo que hará las veces de hilo de Ariadna al otorgar certeza para el regreso al pueblo: “El lejano parloteo, río arriba, de las lavanderas, parloteo que se interrumpía para continuar con un grito, una carcajada, o con los azotes húmedos de la ropa, les hizo percibir la familiaridad del río" (p. 16). Por supuesto, la integración al lugar, el ritmo del juego y la ablución ${ }^{9}$ corren a cargo de Félix:

Félix se les reunió. Al irse acercando, con las manos cóncavas, pegando en la superficie hacía salpicar el agua, a la vez que producían nuevos sonidos para ellos.

Juan, Enrique, Joaquín, olvidando sus temores, e imitando a Félix, también hicieron lo mismo, para continuar arrojándose agua, dándose las espaldas, para no sentir el golpe fustigante y asfixiante. (p. 16)

Luego de este primer juego, están listos para emprender el viaje. Salen del agua y recordemos que están desnudos, pero no miran sus cuerpos mientras se secan sino que observan las hojas que caen del álamo (como las gotas de sus cuerpos) y sus miradas las siguen durante su viaje a la deriva. Es notable el desplazamiento de la atención de los cuerpos hacia las hojas grandes:

Se pararon. Félix se escurrió con sus manos el cuerpo y los demás lo imitaron. La brisa, cuando soplaba, los hacía tiritar, al tiempo que veían cómo se desprendían del álamo las hojas grandes, doradas, plateadas, hasta verlas caer en el río, y seguirlas con la vista fuera de la pocita. Verlas chocar, encallar en esos cementerios fluviales de hojas. Algunas al girar se iban apartando de su fugaz

8 "El baño posee un sentido de purificación y de regeneración. Purificación del cuerpo: ésta se obtiene, según Pitágoras, por las expiaciones y las abluciones. [...] Purificación del alma: la purificación del cuerpo alcanza también al alma, y así favorece la renovación espiritual". Jean Chevalier, Diccionario de símbolos, p. 175.

9 "Las abluciones rituales son un símbolo de purificación por el agua. Etimológicamente: limpian el lodo con que uno está cubierto." Ibid., p. 43. 
retención, hasta volver otra vez a la vida del río. Seguir la favorita hasta que se perdía a lo lejos, para volver a seguir la suerte de otra, de otra, y dejarlas perder río abajo.

De repente se dieron cuenta de que estaban secos. (p. 17)

El narrador (con focalización cero) describe lo anterior desde las percepciones de los personajes, y dado que ellos están más ocupados en seguir las hojas que se lleva el río, la desnudez queda en segundo plano en el fragmento anterior, mas no omitida. ¿Podríamos hablar de una contemplación/erotización disimulada, desplazada como mencioné antes? Es posible, y nos muestra el manejo realizado por López Páez, desde sus primeros relatos, para enunciar las acciones y dejar fuera, mediante distintas elipsis que ocupa en los relatos sobre la infancia, los asuntos en los que el lector debe asumir una postura más activa ante la narración.

Una vez vestidos los niños del pueblo siguen a Félix, quien los guía por un espacio que le es conocido y hasta cotidiano para llegar a un remanso ideal donde podrán recolectar peces; sin embargo, el terreno por donde avanzan los tres amigos no les parece convencional y adquiere, según lo leeremos en la siguiente cita, una sensación especial que los vuelve ajenos e intrusos:

Sin embargo, algo violaban, si emitían sus voces, si se rompía una ramita, todo ayudaba a crear el misterio de la profanación, y de cuando en cuando, perdida, como si viniera de un mundo remotísimo, la carcajada fresca y húmeda de lavanderas. La vereda se fué aclarando. Salieron a una playita, suave, húmeda, cubierta de un musgo verde, y ahí un remanso, un templo circundado de árboles enlamados, de los que colgaban lianas, las que como cortinajes, tamizaban la luz del sol. Félix se volvió, como queriendo decirles: ¿Qué les parece?", pero todos se quedaron mudos, con miedo, llenos de respeto, como si fuera el respeto sentido en el templo, y zuzurrando le dijo Joaquín a Félix: ¿Aquí?"

—Aquí, claro que aquí! —respondió Félix—, pero ¿por qué hablan así? (p. 18)

El mundo adulto, conocido y civilizado, se siente remoto y apenas perceptible gracias a las lavanderas, pero han cruzado un umbral para descubrir un sitio mágico. El sentimiento de profanación de una zona sagrada, con luz tamizada, los paraliza y les parece confirmar que han salido del espacio de los adultos pretendiendo ser libres, pero han arribado a un "templo" que los intimida aún más:

Y veían y veían, y sus sentidos se exparcieron [sic]: el olor, un olor húmedo, rico, cargado de reminiscencias de cosas perdidas; la luz, por un lado la luz brillante, directa, por el otro la luz sutil, la que venía en hilos desde aquella bóveda arbórea, hasta clavarse como alfiretazo en el agua, y la luz verde, y el azul del agua, que como casuya extendida se ribeteaba con el oro del sol. El silencio se hizo de nuevo, el silencio del lugar, su silencio. (p. 19) 
Por supuesto, en este ambiente los sentidos son desbordados por tantos estímulos, mismos que infunden miedos sin precedente en los profanadores y éstos contagian a su guía de tal sensación; además, los invade la culpa y temen por un posible castigo. Todo lo anterior lo conocemos gracias a la perspectiva de los niños que ha adoptado el narrador; además, la conexión con el mundo conocido casi ha desaparecido una vez que arribaron a este sitio sagrado, el hilo que les asegura el regreso parece que está a punto de romperse:

[...] Félix se dejó llevar del encanto sentido por los otros, creyendo en todo momento que se acercaba alguien, un ser equivalente al cura, o al sacristán, que los regañaría por haber hollado el templo. Y ahí, por el ruido de la cascada, aun más leve, se oía cómo azotaban la ropa, pero el ruido era tan remoto, tal como el ruido del sueño, y las voces tan indiferenciadas, que aumentaban el misterio. (p. 19)

Félix, acostumbrado a ese espacio, de igual forma se siente "encantado", lo cual indica que se ha integrado al grupo y comparte el sentimiento, aunque al alzar la voz y preguntar "¿Pescamos?" rompe ese instante y recupera el mando de la expedición; luego de indicar dónde debe pescar cada uno de los niños, Félix acompaña a Joaquín y comienzan a caer los peces, aunque por la rudeza con la que se maneja el hijo del curtidor, la mayor parte no sobrevive ante la silenciosa decepción del resto del grupo. Finalmente deben iniciar el regreso a su mundo cotidiano y dejar atrás este templo natural que recobra su misterio y carácter sagrado, por lo cual no queda otra salida que la huida:

Furtivamente, como si acabaran de robar los tesoros del templo, volviendo sus rostros hacia atrás, esperando los gritos de "iLos ladrones, los ladrones!", se internaron en la vereda contagiando de sus aprehensiones a Félix, que nunca había sentido ese respeto por lugares tan conocidos por él. (22)

Este sitio les permitió una convivencia inusual, tal como ocurre en tantas historias donde el encuentro en sitios donde está presente el agua propicia que fluyan sensaciones de diversa índole. ${ }^{10}$ Pese a que distintos temores los invadieron mientras pescaban, nunca corrieron peligro y regresaron con nuevos conocimientos de la expedición, aunque el retorno y la posterior despedida

10 “En la Biblia los pozos del desierto y los manantiales (fuente) que se ofrecen a los nómadas son otros tantos lugares de alegría y de asombro. Cerca de los manantiales y los pozos tienen lugar los encuentros esenciales; como lugares sagrados, los puntos de agua desempeñan un papel incomparable. Cerca de ellos nace el amor y se preparan los matrimonios. La marcha de los hebreos y el caminar de cada hombre durante su peregrinaje terrenal están íntimamente ligados al contacto exterior o interior con el agua; ésta resulta un centro de paz y de luz." Ibid., p. 54. 
de Félix les provoca otro tipo de interrogantes: “¿Cuándo volverían a ver a Félix? ¿Podrían pescar otra vez y estaría él ahí en la Tenería? ¿Obtendría Félix el permiso de su padre para que los acompañara? ¿Seguiría siendo su amigo? ¿Y si lo hubieran invitado a jugar con ellos en el pueblo?"11 (p. 23). Las preguntas, en apariencia ingenuas, señalan un aspecto importante: la conducta que los protagonistas pueden mostrar en un ambiente distinto al habitual y cómo cambian de acuerdo a las circunstancias. No dejo de mencionar que existen diferencias entre los niños del pueblo y el hijo del curtidor, principalmente la posición económica.

Pese a la distancia social entre el grupo de amigos y Félix, éste ha dejado una honda impresión en Joaquín, quien verá cómo su nuevo amigo "aparece" de la forma menos pensada:

Joaquín se dirigió a su casa. Echó los pescados en la pecera con el deseo de que todos amanecieran vivos. Esa noche soñó que pescaba: jalaba y jalaba el blanco hilo, y nada salía, hasta que ya cansado vió aparecer entre las brillantes aguas el rostro de Félix. (24)

Si ya hemos reparado en los distintos significados del agua, de las pozas y manantiales, así como de la ablución previa a un ritual o iniciación, la pesca no es gratuita en el conjunto de múltiples símbolos que concentra el cuento:

El agua es el símbolo de las energías inconscientes, de las potencias informes del alma, de las motivaciones secretas y desconocidas. Sucede bastante a menudo en los sueños que se esté "sentado al borde del agua pescando. El agua, símbolo del espíritu aún inconsciente, encierra los contenidos del alma que el pescador se esfuerza en traer a la superficie y que deberán alimentarlo. El pez es un animal psíquico..."12

Más aún, según Chevalier y su trabajo al registrar los símbolos:

Pescar, en sentido psicoanalítico, es también proceder a una suerte de anamnesis, en el sentido de extraer elementos de lo inconsciente, no por una exploración directiva y racional, sino dejando actuar las fuerzas espontáneas y recogiendo sus resultados fortuitos. ${ }^{13}$

11 Aunque no se expresen preguntas como lo hacen los personajes del cuento, en la novela $L a$ costa (1980), existe un contraste entre el comportamiento de un grupo de amigos adolescentes mientras están en la costa de Veracruz y el que manifiestan en la ciudad de México, contraste que deja patente el narrador autodiegético.

12 Chevalier, op. cit., p. 60.

13 lbid., p. 823. 
El sueño de Joaquín resulta contundente y revelador, de ahí que el despertar de una admiración, incluso de un deseo homoerótico, hacia Félix sea producto de varias circunstancias: a) los lugares propicios para el encuentro, b) que no haya un sentido negativo ante la desnudez, y c) los saberes prácticos de Félix, así como su pericia de guía/líder. La pesca, entonces, la registramos en dos niveles: los chicos han recolectado algunos peces, y Joaquín ha sido "enganchado" por Félix (sin que haya sido su intención). Coincido con lo que señala Negrín sobre este cuento:

"Frescas y dulces aguas" [...] me parece extraordinariamente logrado. La agilidad de los diálogos y las descripciones, siempre significativas y cargadas de afectividad hacia el paisaje, describen el tránsito de la mera aventura prohibida, llena de excitación, a una experiencia profunda, vinculada a lo sagrado. ${ }^{14}$

Una vez vista la transformación de la aventura, volvamos al "deseo homosexual oculto bajo las frescas y dulces aguas", como también apunta Negrín, mas no como algo que aceche e incluso amenace a los chicos, sino como un impulso que puede brotar como parte de la naturaleza misma. Las distintas "Frescas y dulces aguas" por las que transitó Joaquín nos indican la ruta de juegos y rituales que siguió para ver cómo aparece Félix en sus sueños sin que ese deseo se vea manchado o censurado. Simplemente es un deseo que el narrador (quien no emite juicios ni valoraciones) sólo enuncia y pone a consideración del lector.

\section{"HoRmigas": CUANDO EL MIEDO TE VUELVE PEQUeÑo}

En el segundo relato del libro la figura central es Joaquín, narrador-protagonista que vive los retos cotidianos que aparecen sin cesar en los días de la infancia; en este caso, tiene ante sí una inminente pelea con Nicanor a la típica hora de la salida, pero intenta evadirse y desea vehementemente que algo común o extraordinario ocurra para evitar la confrontación. El motivo de la pelea es la crueldad que el protagonista ejerce con las hormigas, a las cuales les impone todo tipo de pruebas (mientras intenta ahogarlas en el agua) para asegurarse que son merecedoras de su benevolencia, lo cual reprueba su amigo; éste, convertido en un juez implacable, es un adversario formidable y su fama lo precede, por lo cual nuestro narrador huye luego de reflexionar sobre lo dañada 
que quedará su reputación por no hacerle frente a Nicanor. El cuento ofrece un claro paralelismo entre la vulnerabilidad de las hormigas (que están a merced de Joaquín) y la del protagonista que teme porque Nicanor lo golpeará, pero sobre todo lo dejará en evidencia delante de los compañeros de escuela, sus amistades y los vecinos, de ahí que sólo atina a correr mientras le gritan todo tipo de insultos. Veamos los miedos que atenazan al protagonista:

(Me va a pegar. Sí, me va a pegar. Si pudiera irme. Un dolor de estómago. Sí, un dolor de estómago, pero muy fuerte. No me lo va a creer Nicanor. Va a decir que le tengo miedo. ¿Cómo me podré ir, sin que él diga que soy un marica y que le tengo miedo? ¿Y si vinieran de mi casa a buscarme? Mi papá... Puede pasar por aquí, pero... nunca ha venido por mí... Mi mamá: no sale en las mañanas, aunque su comadre Chole vive por aquí y ella vendría a visitarla, cuando acabara la visita podría decir: "Voy por Joaquín", y así no podría decir nada Nicanor. Si viniera mi mamá... Lo malo es que nunca sale en las mañanas y a su comadre Chole no la visita, sino al contrario ella es quien visita a mi mamá. Ya saben los otros que nos vamos a pelear. Rodolfo está haciendo papelitos y se los pasa a Conchita. Me va a pegar Nicanor...) (p. 26)

Joaquín piensa en alguna ayuda providencial para esquivar la pelea, el conflicto central en apariencia y en lo inmediato; sin embargo a lo largo del relato nos percatamos de que, además del miedo a los golpes de Nicanor, el protagonista va revelando otros aspectos de su cotidianidad, como que resiente la falta de atención por parte de sus padres, y que esto se potencia cuando desea (aunque sabe que no ocurrirá) que alguno de ellos acuda por él a la escuela para evitar la pelea; asimismo, el miedo al ridículo y a la mala imagen que ante sus conocidos se generará cuando pierda la pelea, pues Nicanor es más fuerte y habilidoso para luchar, lo tiene totalmente aterrado, más allá de perder o salir golpeado. Será conocido - y ese es su mayor temor- como "un marica". Más adelante veremos por qué lo preocupa tanto este mote.

En el momento decisivo, el personaje principal corre, escapa a pesar de la opinión pública y del costo que esto implica. Una experiencia desagradable y que ocupará un lugar en la memoria, sobre todo por lo que le gritó Nicanor:

Nicanor. ¿Para qué corrí? ¿Para qué corrí? ¿Para qué corrí? ¿Y ahora cómo salgo? ¿Y si me lo encuentro? ¿Pelearme? Ahora sí nunca podré pelearme con él. Y tengo que verlo. ¿Y si no lo viera? ¿Cómo? Voy a verlo mañana. Qué van a decir las muchachas y Rodolfo y Pepe. Mañana. (p. 27)

A la espera de la pelea, y de que algo o alguien lo auxilie, el narrador evalúa sus posibilidades, y aunque son escasas, siempre tiene en mente la huida dadas las evidentes cualidades de su rival: "Me va a pegar. Es más grande. Es más fuerte. Juega futbol. No ha estado enfermo. Yo le gané a las carreras y a subirme al 
árbol. ¿Y si corro?" (p. 28) Joaquín insistentemente dirige sus ensoñaciones a que un evento desafortunado lo salve: un terremoto, la muerte de algún familiar, cualquier motivo para huir de ese trance, lo cual nos habla de una desesperación importante al desear, incluso, el deceso de la mamá de Nicanor. El miedo, sin duda, lo impulsa a buscar las salidas más extremas e incluso reprobables:

Un temblor: corremos a nuestras casas. O el huracán. Me parece que vi nubes "aborregaditas", dicen que después viene el temblor, pero necesita ser fuerte. Tocan a muerto. Tocan a muerto. Esa campana sigue tocando, ¿será de algún rancho? ¿Alguien que mataron? Una viejita. No, la mamá de Nicanor no. No. Ya le habrían venido a avisar. No. No puede ser. Alguien de algún rancho que mataron en una emboscada. Como a mi tío Rodrigo. Mi tía. Si viniera a buscarme... (p. 33)

Retomo el temor del protagonista de ser llamado "marica". Lo podemos identificar claramente con el rechazo que la familia practica hacia su primo Augusto, hijo del difunto tío Rodrigo, muerte trágica que (dicen) lo marcó ante el resto del pueblo y lo transformó en el personaje del que ya no se debe hablar:

(Dicen que así fué como se puso Augusto. Vió a su padre ensangrentado cuando lo bajaban del caballo. De la impresión se desmayó y se quedó horas y horas tirado en el asoleadero. Mi papá no lo quiere. A mi mamá no le gusta que hablemos de él. Ella no habla de él. Nadie quiere hablar de él. Solamente aquel día en que veíamos un retrato a donde estaba Augusto con su papá, mi mamá dijo "ya era así". Mi papá no contestó nada, pero miró el retrato detenidamente y luego miró a mi mamá en los ojos sin decir nada. Dicen que iba a matar a mi papá porque estaba gestionando que lo admitieran en el Colegio Militar. (p. 34)

No pasemos por alto la última declaración de Joaquín con respecto a la reacción que tuvo su primo contra su padre, quien busca normar y corregir al primo Augusto ante la ausencia de su padre. No es gratuito que pretendan hallar una solución en la disciplina castrense: es un lugar común el intento de reformar a los hombres que muestran inclinaciones homosexuales vía el ejército, la religión o pseudo tratamientos clínicos. Para contextualizar esta práctica social y su representación en la literatura, cito a Selden quien explica que

Un interés compartido por los recientes estudios gays e historicistas (Cohen, Katz, Trumbach) ha sido la construcción de la sexualidad en una red de relaciones de poder ejercido a través de las prácticas reguladoras de la Iglesia y el Estado, y de las formas menos evidentes pero numerosas en que la cultura occidental ha circunscrito las relaciones personales ${ }^{15}$

15 Raman Selden, La teoría literaria contemporánea, p. 295. 
Si en el cuento anterior vimos aparecer un deseo homoerótico, que pudo o no desarrollarse en el protagonista, esta preferencia sexual es condenada a la marginalidad y al silencio debido a las presiones familiares y sociales en el presente relato.

Ahora, recuperemos a nuestro protagonista, quien recibe los insultos de Nicanor mientras consuma su precaria liberación, pues al poco tiempo deberá enfrentar a los mismos actores en los espacios de los que pretende alejarse:

Corrí como loco y Nicanor me gritaba. Sí me gritaba. Pude pararme y devolverme. Se oye feo eso que me gritaba, pero ya había empezado. ¿Qué dirá Lolita? ¿Y Rodolfo? Si no hubiera colegio, si yo no viviera aquí. Si fuera hormiga, así que se me olvidara todo, como es... a ¿cuál será? Nicanor. Venía a jugar aquí. El día que le pusimos el cohete al hormiguero. Los huevecillos blancos. Como una bomba. El colegio. Mañana. Lolita. Si una de esas se acerca la subo, hasta que se Ilene la hojita y venga el hundimiento. Una... dos... tres... cuatro... cinco... (p. 37)

Este relato resulta excepcional por la narración consonante: Joaquín es un narrador/protagonista que cuenta sus experiencias y sensaciones con muy poco desfase temporal entre acción y narración; es un niño que da cuenta de sus preocupaciones, miedos y ausencias a pesar de narrar algo muy cotidiano y frecuente. No me detendré en detallar el artificio evidente por parte del autor (un chico no podría estructurar una narración de esa forma), prefiero destacar que posee varias de las constantes a las que recurren (o afectan) los niños protagonistas de la narrativa de López Páez: a) las ensoñaciones de huida, b) los malestares (primero ficticios, luego reales) que padecen para evadirse de los conflictos, c) la relación distante con uno o los dos padres. Ya sea en EI solitario Atlántico (1958), Mi hermano Carlos (1965), pasando por La costa (1980) y arribando a lo más reciente, como Mi padre el General (2004) o ¡A huevo, Kuala Lumpur! (2010), los niños que protagonizan las historias muestran que la infancia no es un época deliciosa en todos los casos.

\section{CONCLUSIONES}

Los cuentos que se revisaron en las páginas anteriores dan muestra de la calidad narrativa que desde un primer momento caracterizó a Jorge López Páez. En "Frescas y dulces aguas" constatamos el proceso de doble iniciación al que asiste un grupo de amigos: mediante un ritual acceden a un sitio "sagrado" (desde su perspectiva permeada por el mundo adulto, la cual es verbalizada por el narrador externo) y uno de ellos, Joaquín, visualiza mediante un sueño 
el deseo (quizá reprimido) que despierta en él la personalidad de Félix. Llama la atención que los distintos lugares por los que transitan, luminosos todos ellos, nos dan cuenta de que el acercamiento de los niños y Félix no se oculta en la oscuridad ni en espacios cerrados, aunque ciertamente fue posible en un sitio donde las normas del mundo adulto y heteronormativo pierden fuerza debido al aislamiento; aun así, el relato carece de juicios por parte del narrador, característica de los enunciadores empleados por López Páez ya sea para recuperar la infancia, ya para relatar experiencias homoeróticas.

En"Hormigas"vemos, por el contrario, a personajes que resienten las presiones sociales, ya sea el protagonista con los distintos miedos que cotidianamente lo aquejan (y más con una pelea próxima), o el primo excluido del que no hay que hablar, pues aunque no se enuncie con claridad, las preferencias del primo Augusto lo han marginado de la familia y quizá de las amistades. Vemos así una sanción hacia dicho personaje.

Encuentro en Los mástiles los primeros desarrollos de la iniciación homoerótica y la censura sobre los personajes con distintas preferencias sexuales, así como de la infancia como una etapa de miedos y soledad, aspectos que serán trabajados con amplitud en la narrativa de López Páez. Si bien la infancia está acreditada desde los primeros cuentos, la temática homosexual apenas se vislumbra, se trata tangencialmente la preferencia de los personajes. Pese a ello, no dejo de señalar que estos atisbos nos inician en la amplia y reconocida trayectoria que ha consolidado el maestro veracruzano para que su narrativa sea uno de los referentes más importantes en la literatura gay de nuestras letras.

En cuanto a la infancia, basta mencionar que López Páez exploró desde sus primeros textos el tema que se ha constituido en un importante eje de su vasta obra; además, el maestro veracruzano fue parte de un nutrido contingente de escritores y escritoras que emerge en el medio siglo y dirige sus esfuerzos creativos a dar voz a los infantes que (hasta ese momento) en su mayoría habían sido personajes secundarios o sin relevancia en cuentos y novelas. A partir de la década de 1950, la vuelta a una de las primeras etapas de la vida tomará un impulso inusitado y aparecerán numerosas narraciones sobre la infancia y la adolescencia en la literatura mexicana contemporánea, de las cuales algunas de las más valiosas son de la autoría de Jorge López Páez. Por ese motivo, retomo para finalizar este acercamiento a Los mástiles las palabras de Edith Negrín: "La obra de López Páez merece ser más estudiada." 
BibLIOGRAFÍA

CheValieR, Jean y Alain Gheerbrant, Diccionario de símbolos. Traducción Manuel Silvar y Arturo Rodríguez. Tercera edición actualizada. Barcelona: Editorial Herder, 1986.

López PÁez, Jorge, Los mástiles. México, Los presentes, 1955.

Muñoz, Mario, "El cuento mexicano de tema homosexual", en, Cuento mexicano reciente: aproximaciones críticas. Samuel Gordon (comp. y ed.). México, Ediciones Eón/The University of Texas at El Paso, 2005, pp. 115-129.

NeGrín, Edith. "Cuentos para vencer a la muerte", en Cuento muerto no anda (La ficción en México). Ed. y prólogo de Alfredo Pavón. Tlaxcala: Universidad Autónoma de Tlaxcala / Instituto Nacional de Bellas Artes / Consejo Nacional para la Cultura y las Artes / Instituto de Cultura de Tlaxcala, 2004, pp. 43-80.

Selden, Raman, Peter Widdowson y Peter Broker. La teoría literaria contemporánea. Traducción Blanca Rivera de Madariaga. Tercera edición actualizada. Barcelona: Ariel, 2004 (colección Ariel Literatura y Crítica). 